\title{
Infectious Diseases and the Last 100 Years in the American Pediatric Society
}

\author{
FLOYD W. DENNY, JR
}

Department of Pediatrics, University of North Carolina School of Medicine, Chapel Hill,North Carolina 27599

Infectious diseases have been, and continue to be, major problems in the lives and deaths of children. While trying to put the last 100 years into perspective for you, I was a little shocked when I realized that I have been a firsthand observer for almost half of this time. The younger among you and those not involved in a daily way with infectious diseases probably have not stopped to think about the changes in this area of pediatrics. We have come a long way these past 100 years-but I add quickly that we have a long way to go. In the next few minutes, I will describe some of the changes that have taken place since 1888 . I will show you examples of the members of our Society who helped make these changes. I will mention some of the things about infectious diseases that have caught my fancy and, finally, I will speculate on what the future holds for our discipline.

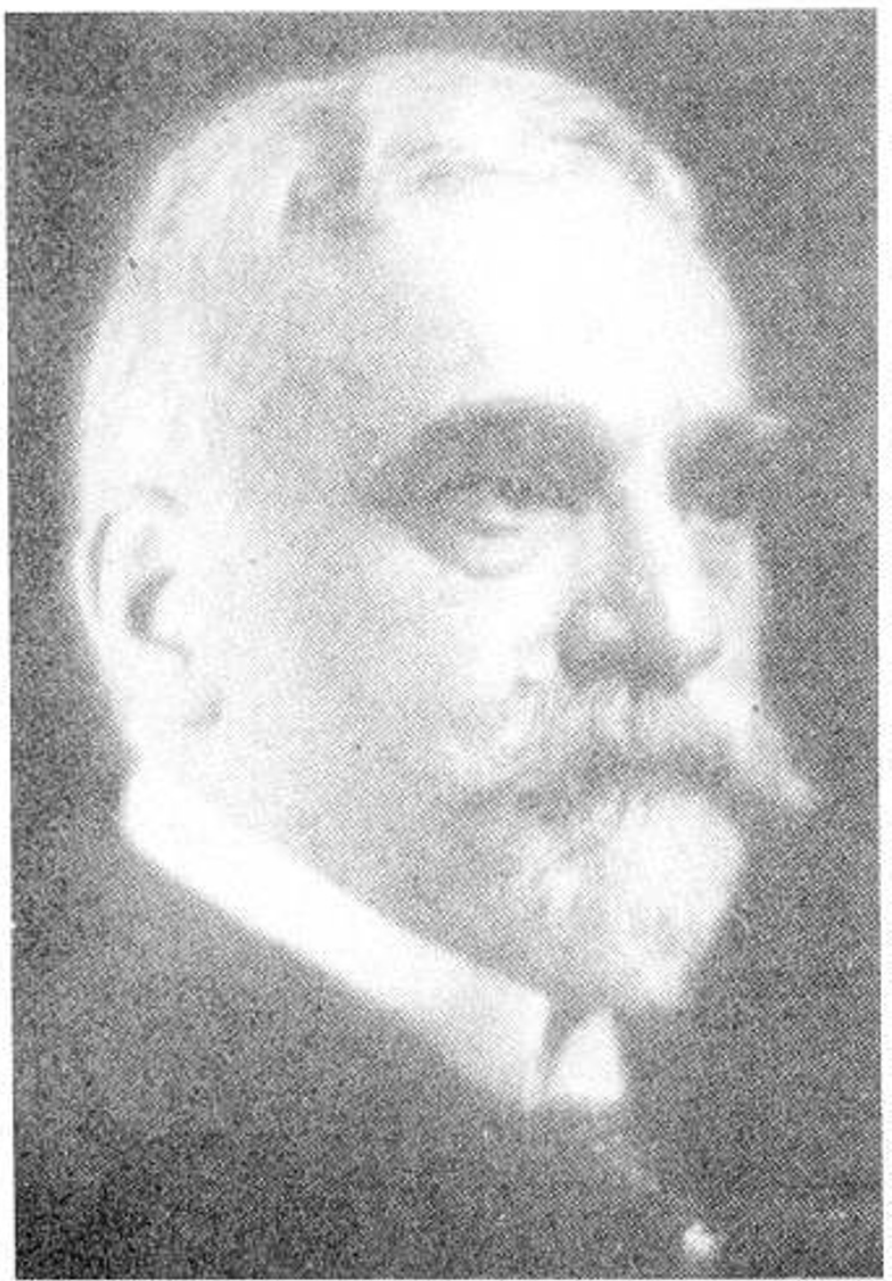

Fig. 1. Henry E. Koplik. From Pediatric Profiles, by Veeder BS, St. Louis, CV Mosby, 1957, p 78 (Used with permission.)
It is 1888 , the start of a period described by Faber and Mclntosh (1) in their History of the American Pediatric Society as "Darkness and Dawn." Life expectancy is less than 50 years, infant mortality is well over 150 per 1000 births, and neonatal mortality approaches 50 per 1000 births-a horror story by modern standards (2). Public hygiene is deplorable and infectious diseases are the dominant causes of morbidity and mortality among children. The science of bacteriology has just been born; viruses are unknown. Faber and McIntosh provide good examples of the situation at the turn of the century. During the first 14 meetings of the APS, $92 \%$ of the papers about the 10 most frequently presented topics addressed infectious diseases. Diph-

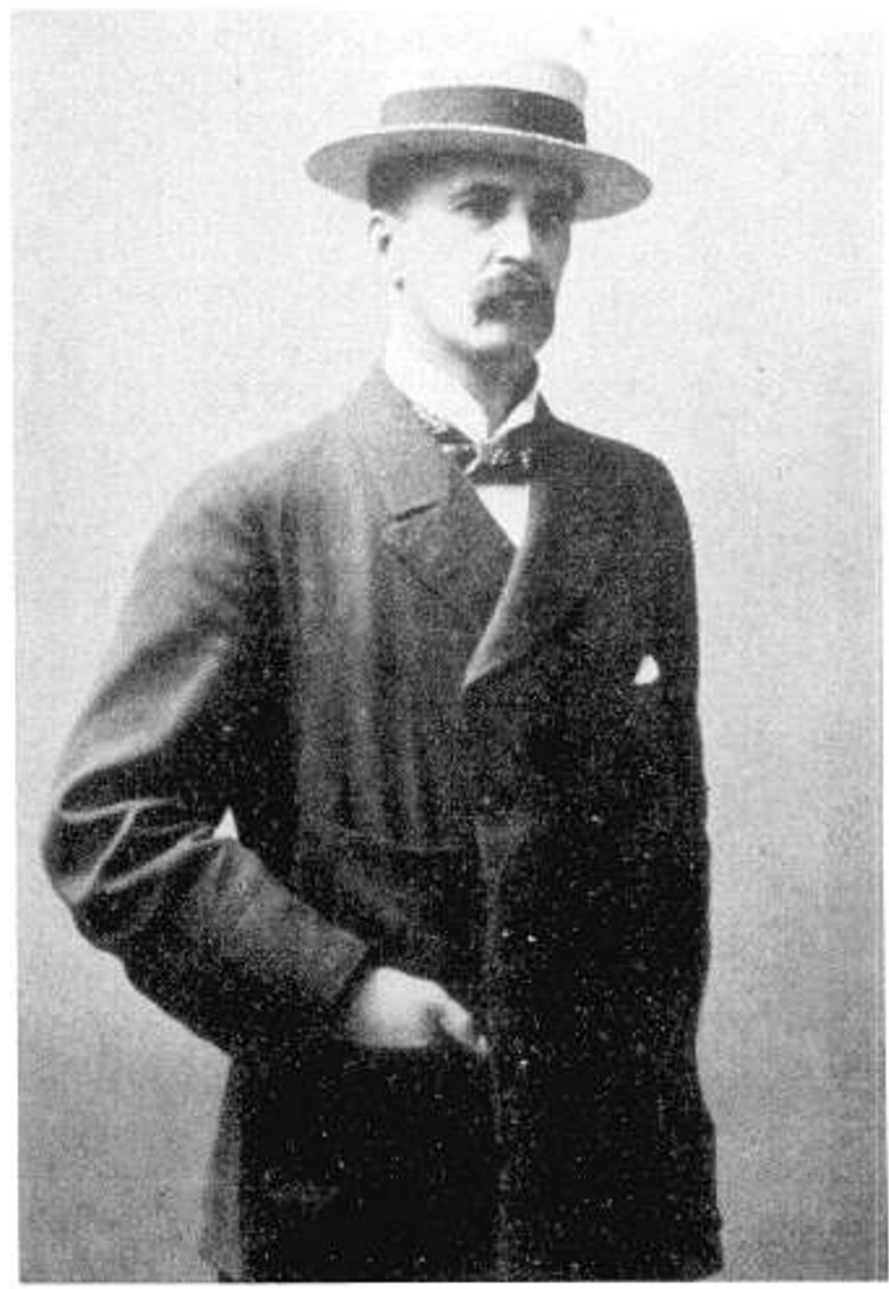

Fig. 2. William Osler, Taken at Toronto, 1896. From The Life of Sir William Osler, Vol. 1, by Cushing $\mathrm{H}$, Oxford at the Clarendon Press, 1925. p 360. 


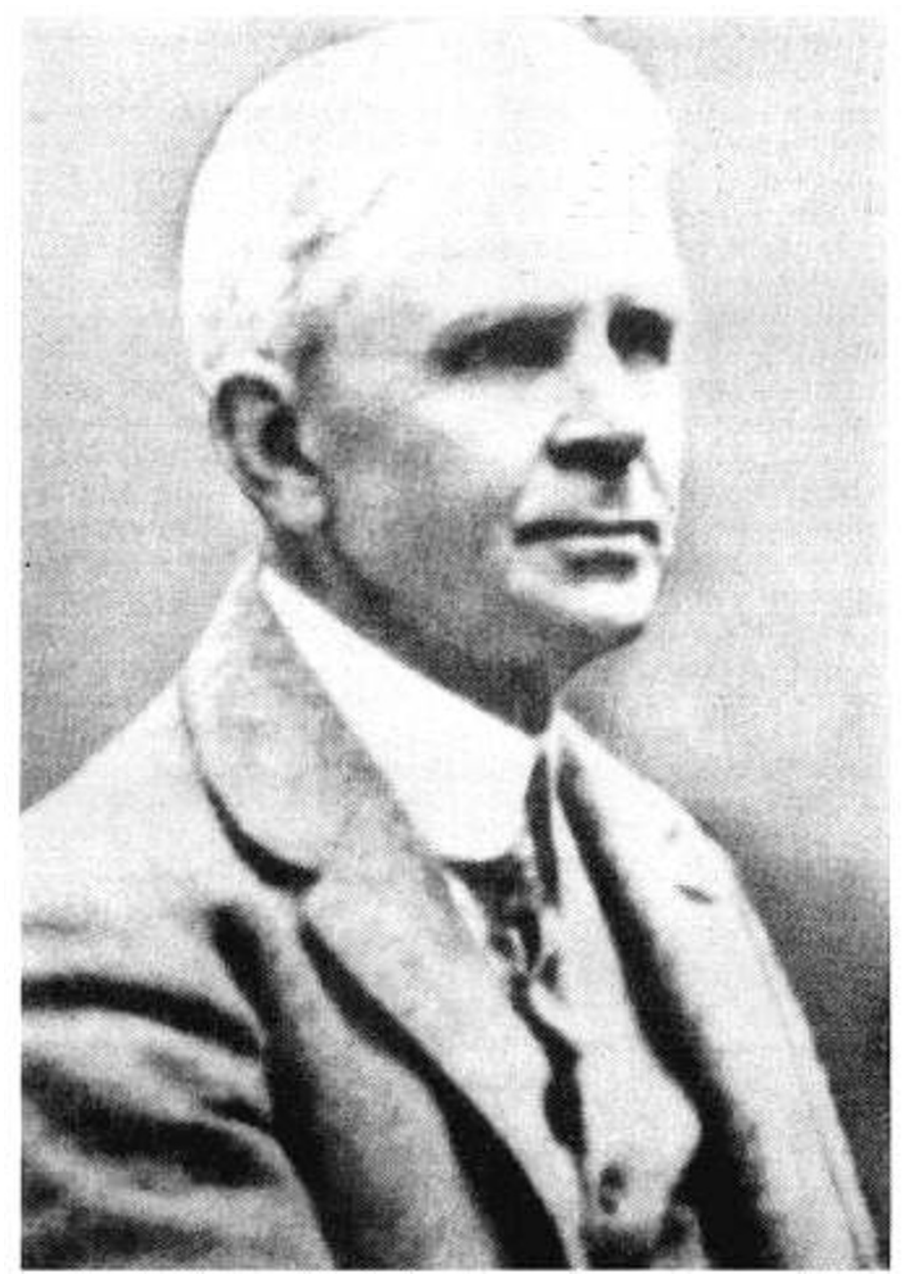

Fig. 3. Luther Emmett Holt. From Pediatric Profiles, p 33. (Used with permission.)

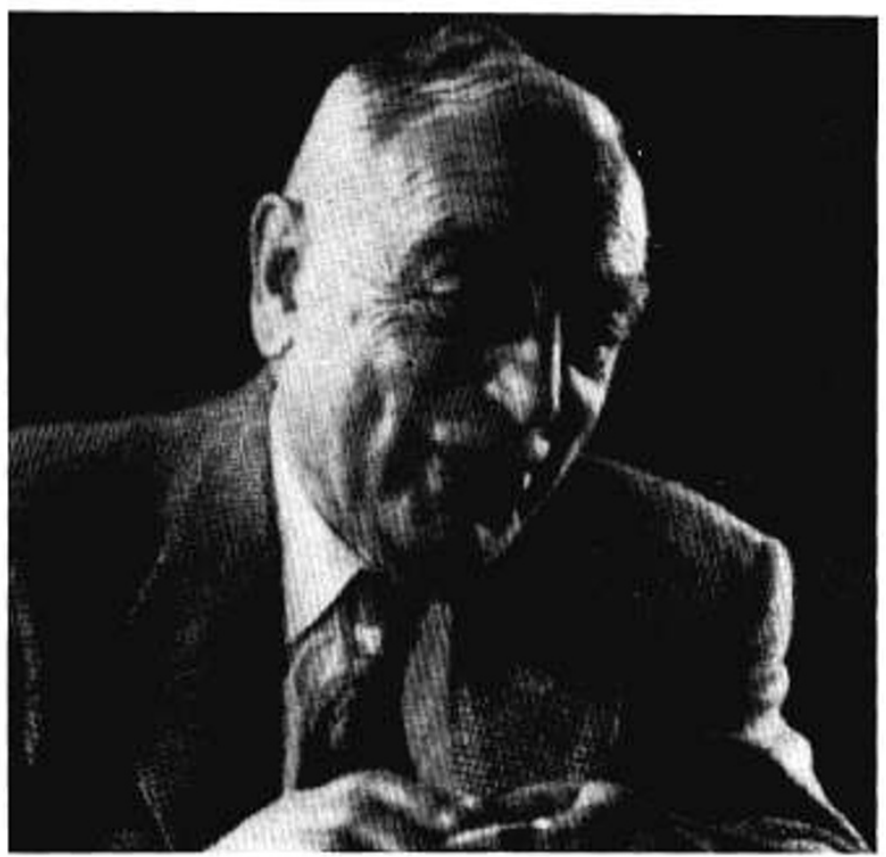

Fig. 4. Bela Schick. From Pediatric Profiles, p 247. (Used with permission.) theria dominated the meetings; more than $25 \%$ of the papers concerned this infection, which was almost invariably fatal when the larynx was involved. The use of gargles, sprays, and local injections was reported with variable and modest success, but the use of the O'Dwyer intubation tube, the forerunner of the modern endotracheal tube, received most attention. In one study, $26 \%$ of 350 cases recovered, a remarkable success at that time. In 1895 , antitoxin was introduced. Its success prompted a formal resolution of the Society attesting to its benefit. Henry Koplik (Fig. 1) was active at this time and described an office incubator to be used in the rapid identification of the diphtheria bacillus. He appears frequently in early APS history and was its president in 1900. Interestingly, the discovery of his "spots" in measles, for which he is best remembered, was not reported at an APS meeting. Tuberculosis was a serious and common problem. William Osler (Fig. 2), shown here in 1896, was prominent in the APS before going to Oxford, and he reported on several infectious disease topics, including one on the pathology of tuberculosis. Diarrheal diseases were the largest killer of very young children; pasteurization was described in 1896 at one of our meetings. Scarlet fever was also a dreaded disease. Emmett Holt (Fig. 3) reported a mortality rate of $55 \%$ in children under 2 years of age. Although Holt is best known in the metabolic arena, he reported frequently in the early years on infectious disease problems, including pneumonia, meningitis, and diphtheria. Rheumatic fever, pertussis, and tetanus were serious problems and small pox was present, though not as large a problem as might be expected. The lumbar puncture was de-

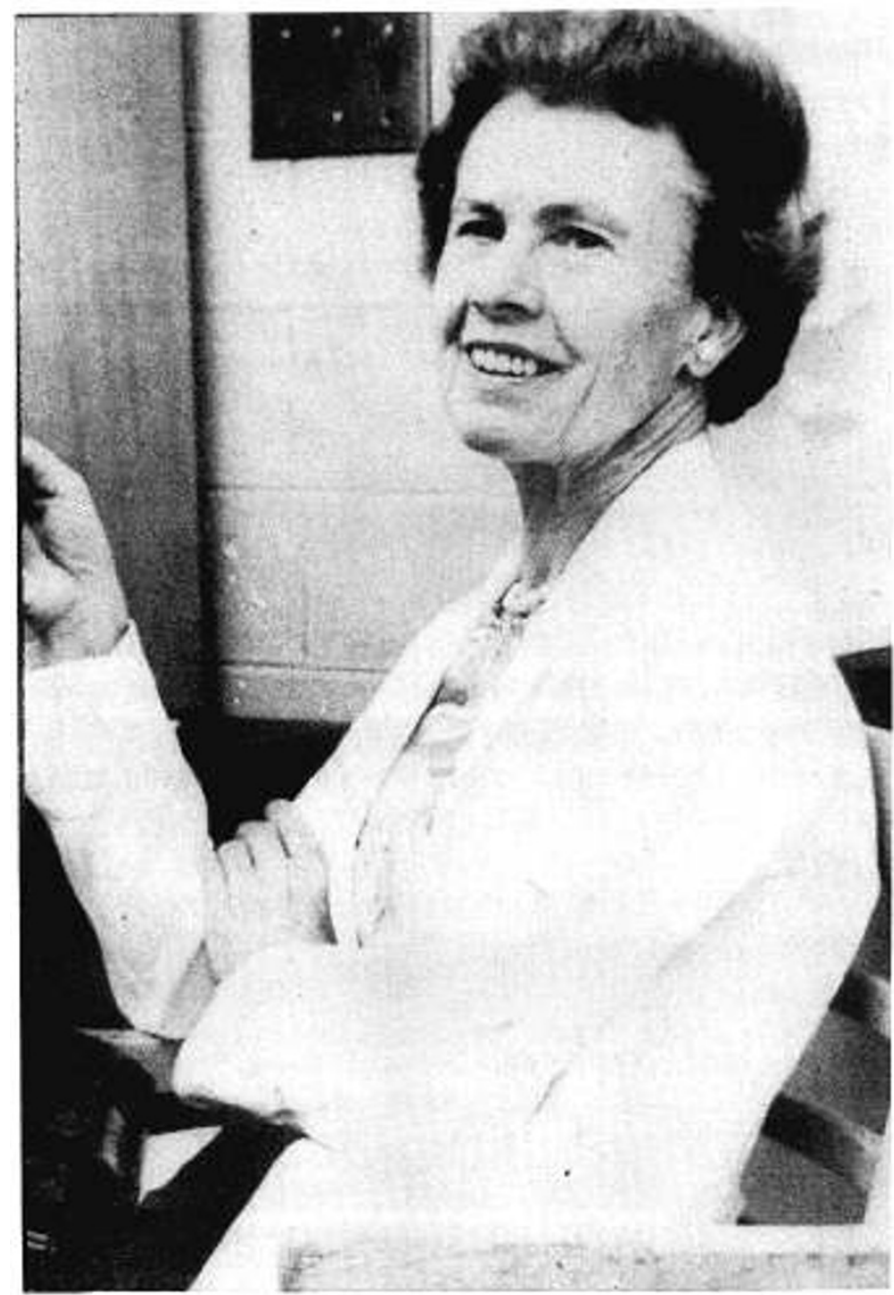

Fig. 5. Hattie E. Alexander. Kindly furnished by Michael Katz. 
scribed at one of our meetings in 1896. At about the same time, there were papers describing the differential points of the exanthems, scarlet fever, measles, and rubella. The seriousness of the infectious diseases problem was exemplified by Holt's report of a $50 \%$ case fatality rate of children admitted during the first years of Babies Hospital, which was established in 1887 (3).

This was the darkness. Antiserum for diphtheria heralded the onset of the dawn. Antiserum for meningococcal meningitis was introduced in the early 1900 s, as was the first antimicrobial, salvarsan, for syphilis. Pasteurized milk and other hygienic measures helped to reduce diarrheal diseases. Although infectious diseases continued to be huge problems in the first 50 years of the APS, the light at the end of the tunnel was apparent.

We progress to 1938; the APS is 50 years old. Life expectancy has increased to over 60 years, infant mortality is now in the $50 \mathrm{~s}$, only one third of what it was in 1888 , and neonatal mortality is about 30 per 1000 births (2). Public hygiene is vastly improved and diarrheal diseases, although still a major problem, are under better control. This is the time when pediatrics was gearing up for the future. Diphtheria toxoid has been described and soon will replace toxin-antitoxin. Filterable viruses have been discovered; influenza and other viruses are being demonstrated. Sulfonamides, first reported to the Society by Schwentker for the treatment of meningococcal meningitis, mark the start of the antimicrobial era (1). Bela Schick (Fig. 4) was one of the most prominent investigators of this time period and his observations on diphtheria were forerunners of modern immunology. The period is marred by the onset of World War II when the health

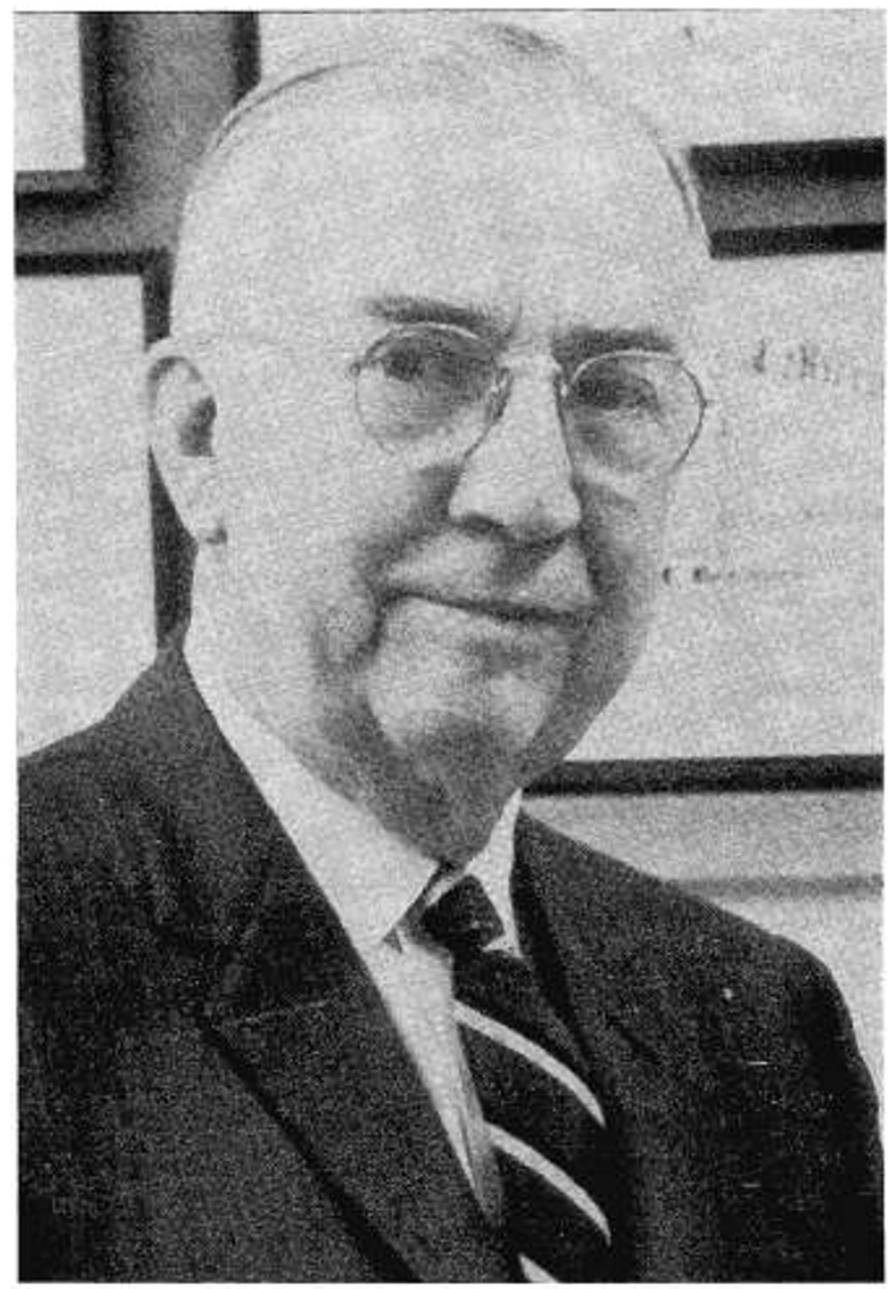

Fig. 6. William L. Bradford. Kindly furnished by William D. Bradford. of children was placed behind the war effort. Even so, the war marked the advent of great advances in infectious diseases.

The years that followed heralded the era of modern infectious disease and a series of remarkable Society members made important contributions. Hattie Alexander (Fig. 5) was dedicated to Haemophilus influenzae. She developed an effective antiserum for the treatment of meningitis and made important observations on the genetics of this bacterium which paved the way for modern studies. William "Brad" Bradford (Fig. 6) made his contributions in the pertussis field. I suspect that few of the younger pediatricians in the audience know about the Bradford wire or loop, a flexible, cotton-tipped swab for culturing Bordatella pertussis from the nasopharynx. I am biased in including Amos Christie (Fig. 7) because he introduced me to pediatrics and was my early mentor. Although not trained in infectious diseases, he made a remarkable contribution. He recognized that most pulmonary calcification in middle Tennessee was not tuberculosis and subsequently recognized its association with Histoplasma capsulatus, thus paving the way for subsequent studies in histoplasmosis. John Enders (Fig. 8), along with two of our present members, Fred Robbins and Tom Weller, was the recipient of the Nobel Prize for growing the virus of poliomyelitis in tissue culture, thus opening the door to a new era in vaccine research. Enders' development of the measles vaccine was another monumental contribution. I include Charlie Janeway (Fig. 9) because his work was so important in the early years of immunology. Edith Lincoln (Fig. 10) taught us all so much about tuberculosis. Finally, Lewis Wannamaker (Fig. 11) along with Rammelkamp

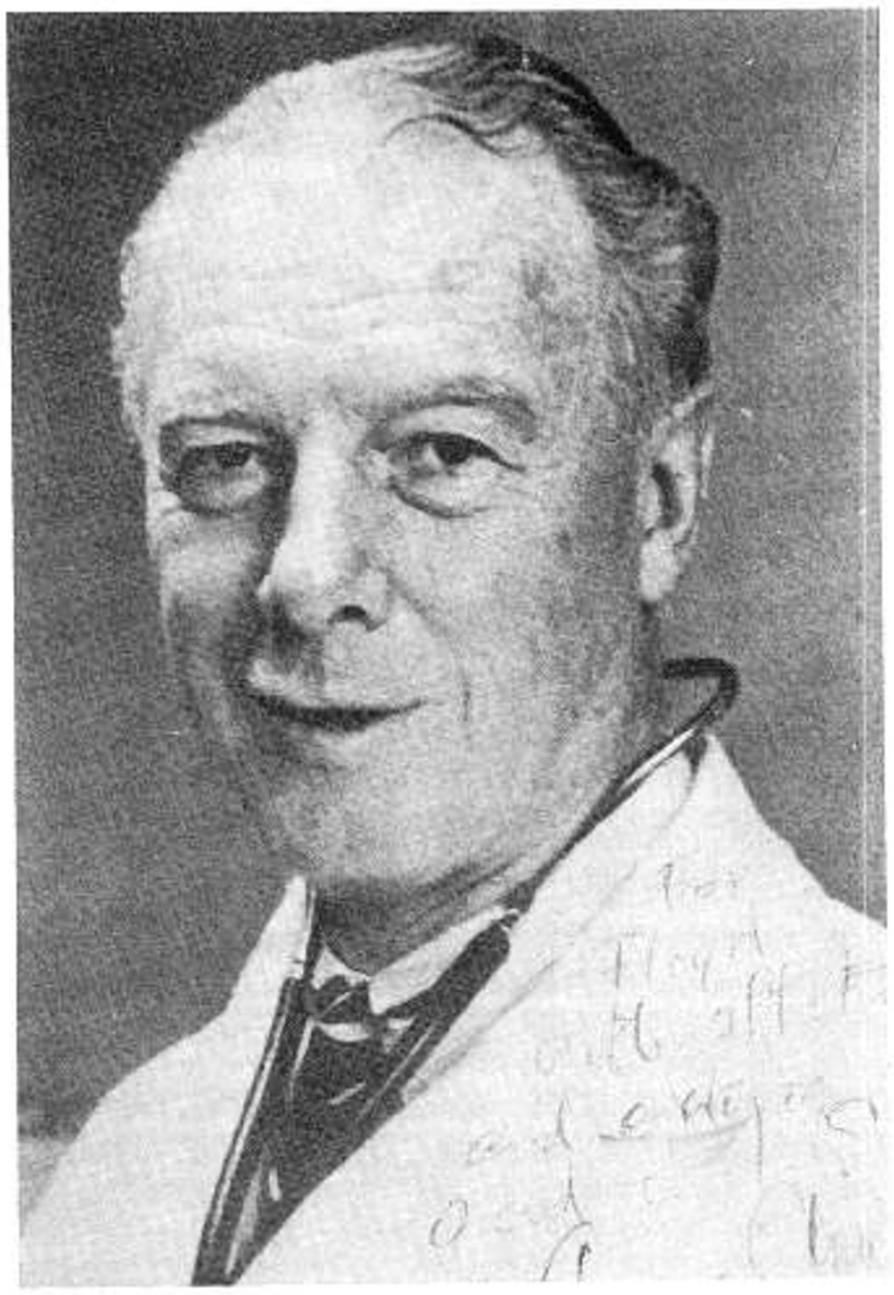

Fig. 7. Amos Christie. 


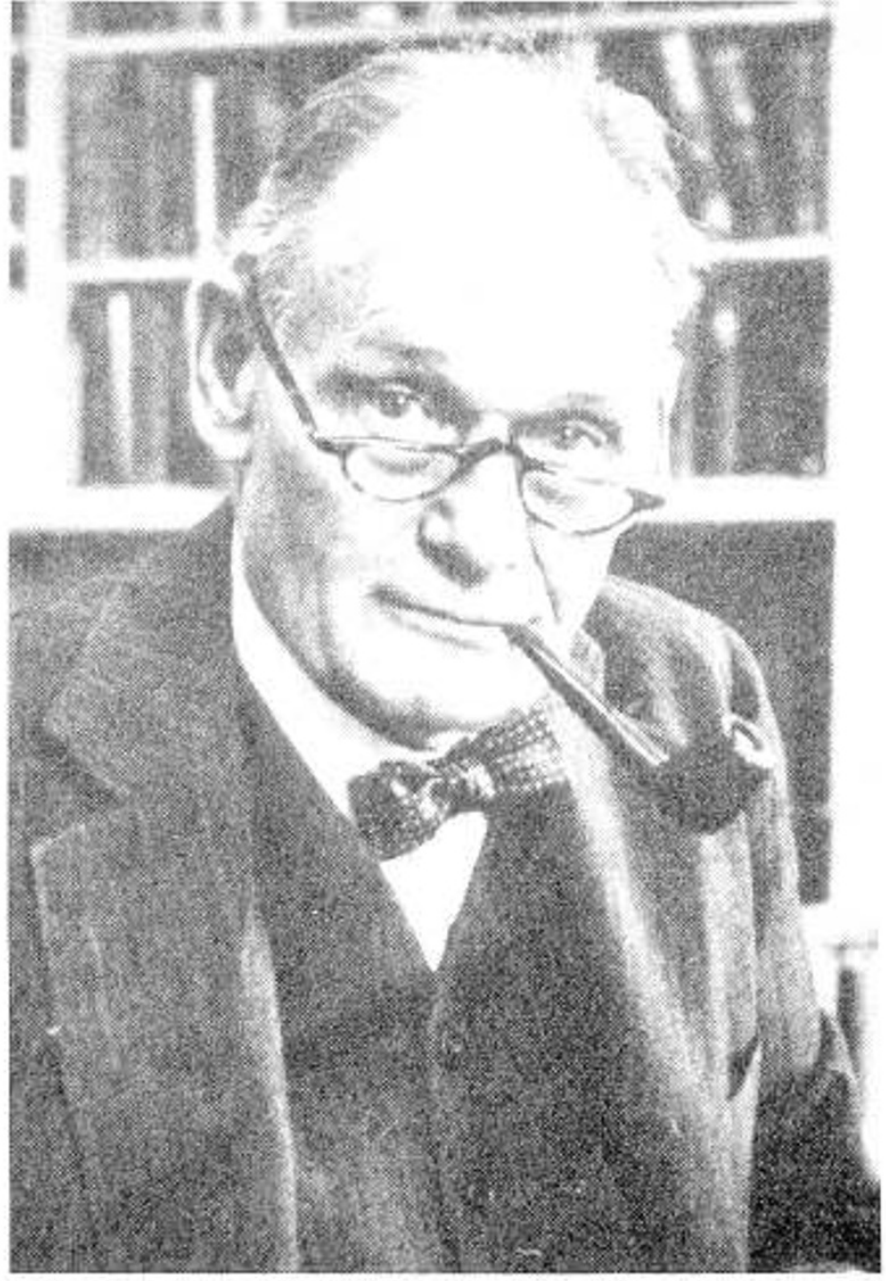

Fig. 8. John F. Enders. From The Children's Hospital of Boston: "Built Better Than They Knew," by Smith CA, Boston, Little, Brown and Company, 1983, p 241. (Used with permission.)

and others, led the effort to control the group A streptococcus and rheumatic fever.

We then reached the time of this centennial. Life expectancy is well over 70 years, infant mortality is around 10 per 1000 births, and neonatal mortality is about the same (2). The role of the environment in infectious diseases is less than in past years but still of considerable importance. The spread of Legionnaire's disease through ventilating systems, the recent report of the spread of salmonella through intact eggs, and the spread of infections in hospitals are examples of this ever-present problem. The isolation of viruses has made it possible to identify, and therefore study in depth, many infections-a feat that was impossible only a few years ago. The entire spectrum of infections has changed drastically. Antimicrobials have made remarkable changes in the infectious diseases picture. Tuberculosis is a treatable disease. I remember so well those days when a diagnosis of tuberculosis meningitis was a death sentence-these children were discharged so they could die at home. Pneumococcal lobar pneumonia is rarely fatal today and complications of respiratory infections, with the exception of otitis media, are infrequent. One of the great plagues of mankind, smallpox, has been eradicated from the world, due in no small part to one of our past presidents and Howland Awardees, Henry Kempe (Fig. 12). One of the great success stories of all times, the development and use of vaccines against certain communicable diseases is demonstrated in Table $1(4,5)$. With the exception of tetanus, all have been reduced by more than $98 \%$. Instead of these diseases on our wards and in our clinics, we are now caring for children who have infections because they have had their host defenses altered. Although AIDS is still relatively uncommon in children, it is occurring too frequently and, in my opinion, is the greatest infectious disease menace of this century.

The technology of our specialty has been developed so fantastically that it remains within our grasp to do things in the laboratory that would have been considered impossible only a few years ago. You have heard from Bob Chanock of the advances that have been made in the vaccine field and the amazing prospects for future vaccines. Dick Johnston has told us that now or in the very near future we have the prospects of altering the host in other ways that will allow it to protect itself against a multitude of infections. Thus, the likelihood for advances in preventing and treating infectious disease is brighter than ever before. I have been increasingly concerned in recent years, however, with the problems of the appropriate application of this knowledge to large numbers of people-that is, population groups. The behavior of people is such that they are increasingly reluctant to participate in scientific investigations; the litigenous nature of our society is accentuating this. Coupled with this are the problems in doing this type of clinical and epidemiological research. In spite of these difficulties, progress is good and bodes well for the future.

I want to take this opportunity to pay tribute to a few of our present Society members who have contributed greatly to the field of infectious diseases. I do this realizing that I am biased in my selection and that I will inevitably leave out some highly deserving individuals; I apologize to them in advance. I have already mentioned Nobel Prize winners Fred Robbins and Tom Weller and their contributions to the conquering of poliomyelitis.

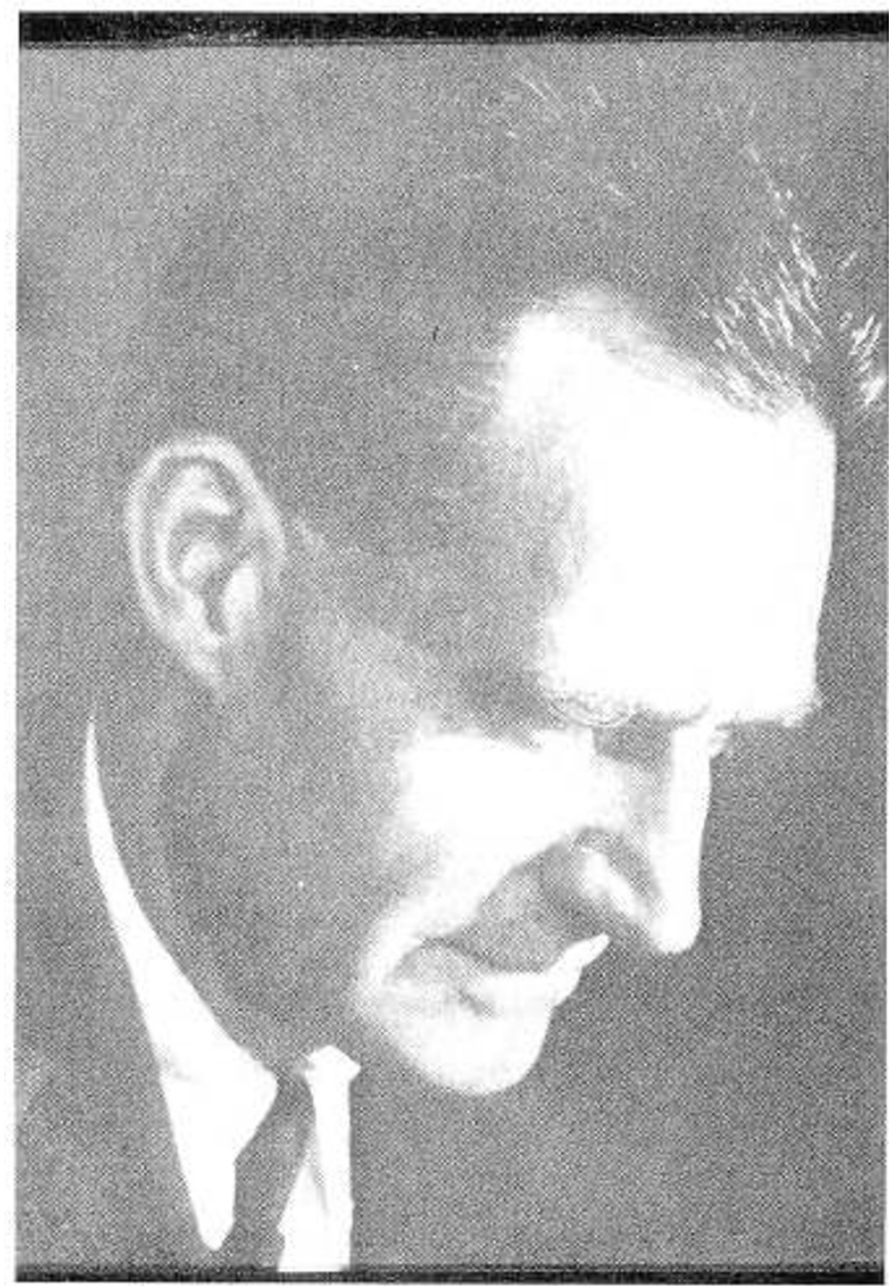

Fig. 9. Charles A. Janeway. From The Children's Hospital of Boston: "Built Better Than They Knew," p 248. 


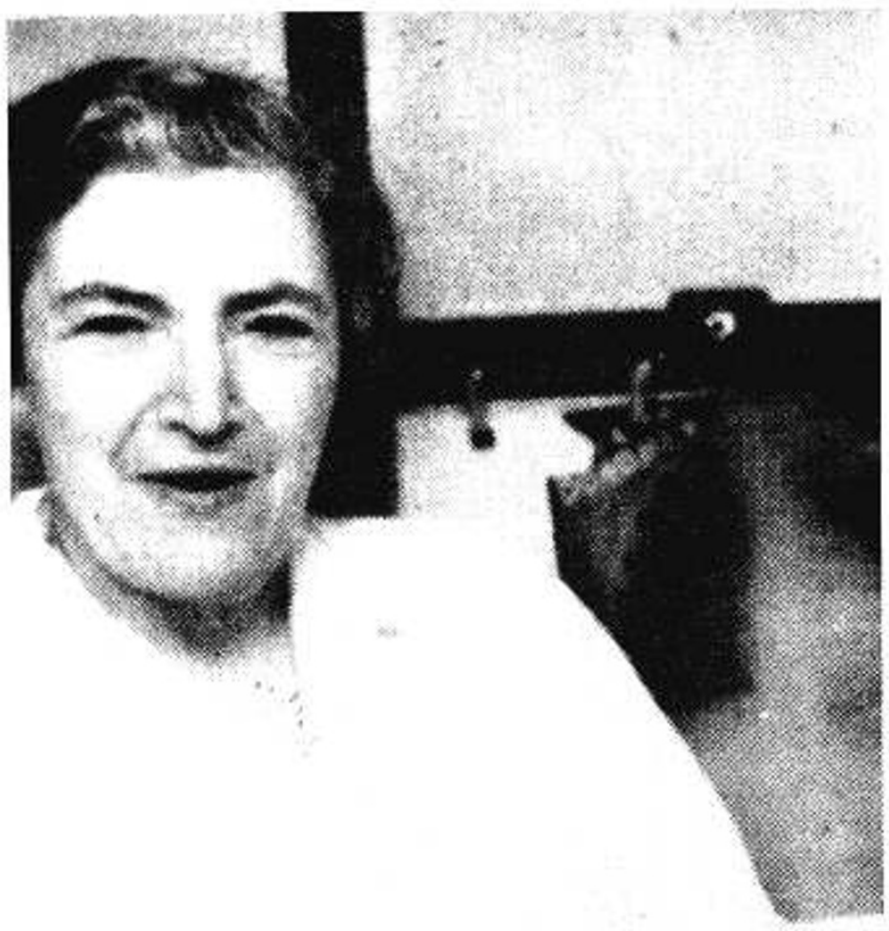

somenter

coli as the most common cause of neonatal sepsis and meningitis. Then there is the story of the 80/81 strain of Staphylococcus aureus, which caused thousands of infections and many deaths, especially in newborns and after surgery. It is still a mystery why these infections appeared in the 1950 s and then disappeared after a few years. The disappearance of rheumatic fever is of special interest to me. This certainly was not due entirely to penicillin treatment; the real reasons are unknown. We watch with some fascination the possible recent resurgence with its beginning in Utah (6). These are but examples of the panorama of infectious diseases as I have witnessed them, and I predict this will continue into the future, adding to the allurement of our specialty.

This brings me to my final point: what else does the future hold for infectious disease and its proponents? I predict that laboratory research will continue to flourish; you have heard two examples of what this form of research has to offer. It will flourish because it forms the basis of most of our future progress. I predict that more and more efforts will be directed to prevention of disease and relatively less to therapeutics. I hope that we will give adequate attention to applying our knowledge to people. We must solve the problems with infectious diseases that exist in socioeconomically deprived groups in our country. Blacks and the poor are inadequately immunized and have more than their share of infections.

Finally, there is the overwhelming problem of infections in children of the Third World; the situation there is where we were between 50 and 100 years age. Seventy-five percent of the world's children under five years old live in Third World countries but re the cause of most of these deaths, infections that, by and

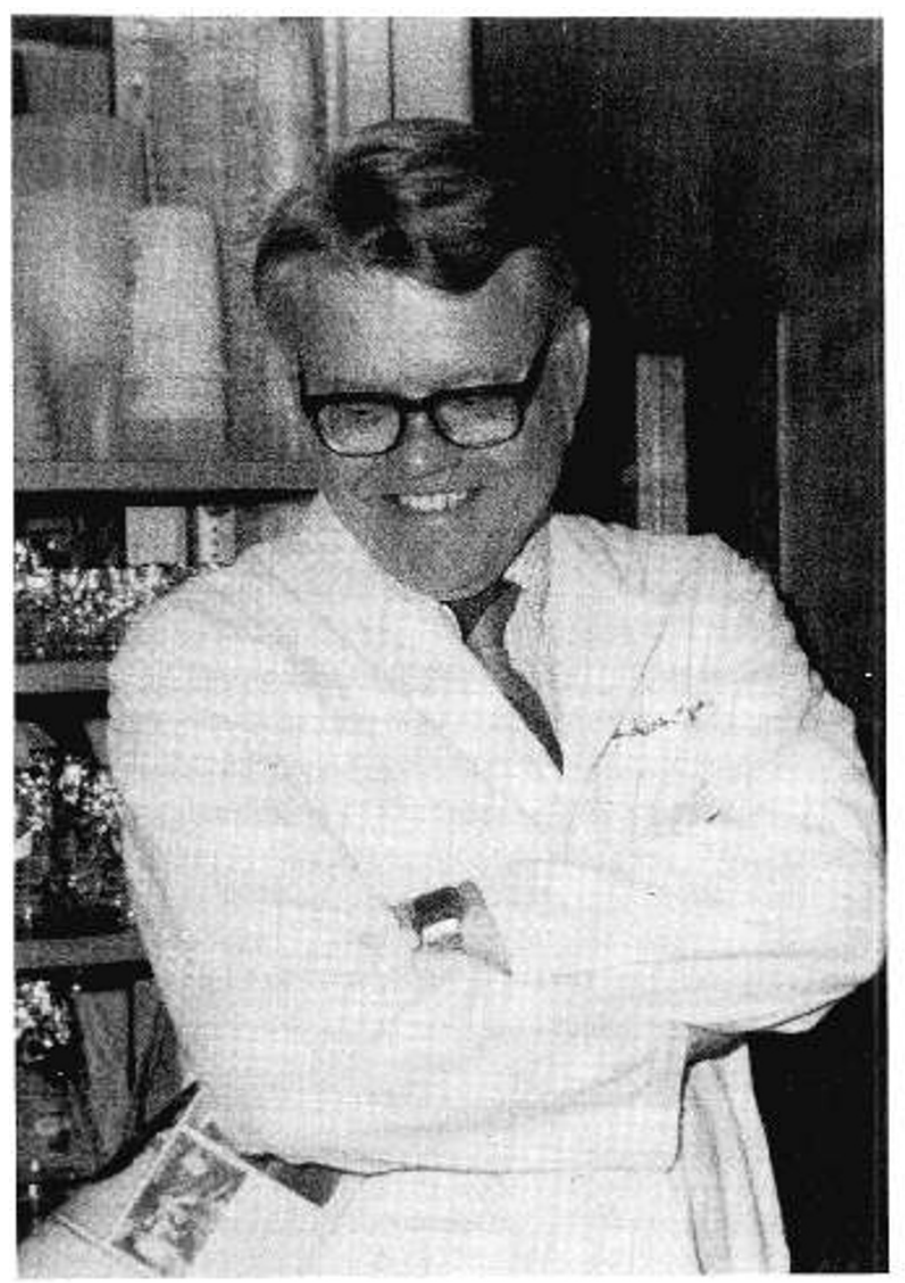

Fig. 11. Lewis W. Wannamaker.

Carlton Gajdusek, also a Nobel Laureate, is contributing mightily to our knowledge of slow viruses and the plight of Third World children-we will hear from him later this afternoon. Saul Krugman, our moderator, has made innumerable contributions, mostly in the area of the prevention of infections. Albert Sabin's contributions have been so great that few people, either lay or medical, are not aware of them. I include Margaret Smith and Horace Hodes in dual roles; they are remarkable investigators and teachers. I know that I have been greatly affected by them. Few realize that Maclyn McCarty is an APS member. He, along with Oswald T. Avery and Colin MacLeod, made what is probably the most important biologic discovery of the century-that genes are made of DNA. Lewis Thomas, also an APS member, is known to all of you because of his medical leadership and as an author.

One of the special fascinations to me of infectious diseases has been the changing patterns of the illnesses we see. I speak here of those changes that appear to occur naturally and are not due to manmade maneuvers, such as those already mentioned. There are numerous examples of infections that apparently are new to the scene, or at least were not recognized: Kawasaki disease, Legionnaires' disease, Lyme disease, cat scratch disease, and toxic shock due to Staphylococcus aureus. Then there are those diseases that were around but the causative agents were not recognized: infections due to Mycoplasma pneumoniae, the atypical mycobacteria, chlamydia, pneumocystis, yersinia, and campylobacter. It has been recognized that our benign old friend, Escherichia coli, is responsible for a large segment of diarrheal disease. The group B streptococcus has assumed the role of $E$. 


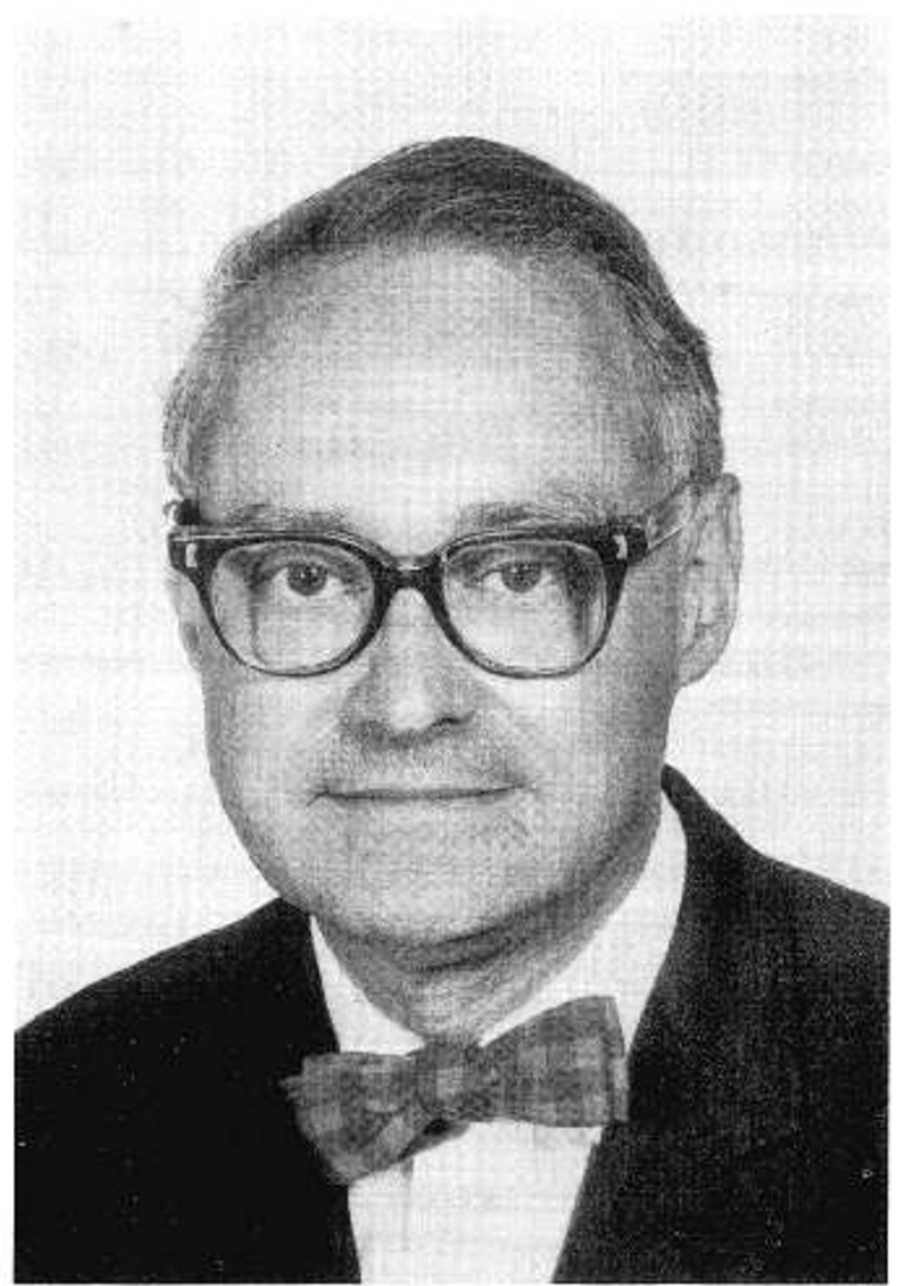

Fig. 12. Henry C. Kempe. Kindly furnished by Margaret Cherryhomes.
Table 1. Comparison of maximal and current morbidity of vaccine-preventable diseases

\begin{tabular}{lrrc}
\hline & $\begin{array}{c}\text { Maximal cases } \\
\text { (year) }\end{array}$ & 1985 & $\begin{array}{c}\text { Percent } \\
\text { reduction }\end{array}$ \\
\hline Measles & $894134(1941)$ & 2704 & 99.7 \\
Mumps & $152209(1968)$ & 2886 & 98.1 \\
Rubella & $57686(1969)$ & 604 & 98.9 \\
Diptheria & $206939(1921)$ & 2 & 100 \\
Pertussis & $265269(1934)$ & 3275 & 98.8 \\
Tetanus & $601(1948)$ & 71 & 88.2 \\
Poliomyelitis (paralytic) & $21269(1952)$ & 5 & 99.98 \\
\hline
\end{tabular}

large, are not serious problems in our country. They can be controlled. Malnutrition is a huge problem, of course, but not by any means the only reason for the predominance of infections. Infections of the respiratory tract and diarrheal disease are the primary causes of increased morbidity and mortality and should receive most attention. In my opinion, the problems of infections in Third World children must receive high priority; the world today is too small and all children too important to do less.

\section{REFERENCES}

1. Faber HK. Mclntosh R 1966 History of the American Pediatric Society 1887 1965. McGraw-Hill, New York

2. Vital Statistics of the United States. 1987. U.S. Department of Health and Human Services Public Health Service, National Center for Health Statistics

3. Babies Hospital, A Century of Caring 1887-1987 (brochure) 1988 The Presbyterian Hospital of the City of New York. Easton Press, New York

4. Hilleman MR 1985 Newer directions in vaccine development and utilization. J Infect Dis 151:406-419

5. The Office of Disease Prevention and Health Promotion, U.S. Public Health Service, U.S. Department of Health and Human Services 1988 Disease Prevention/Health Promotion: The Facts. Bull Publication Co, Palo Alto, CA, p 154

6. Veasy LG, Wiedmeier SE, Orsmond GS, Ruttenberg HD, Boucek MM, Roth SJ, Tait V, Thompson JA, Daly JA, Kaplan EL, Hill ER 1987 Resurgence of acute rheumatic fever in the intermountain area of the United States. N Engl J Med 316:421-427

7. Grant JP (ed) 1986 The State of the World's Children, 1986. Published for UNICEF, Oxford University Press, Oxfordshire, UK 